\title{
Glaciological conditions in seven contrasting regions estimated with the degree-day model
}

\author{
Roger J. BRAITHWAITE, ${ }^{1}$ Sarah C.B. RAPER ${ }^{2}$ \\ ${ }^{1}$ School of Environment and Development, University of Manchester, Manchester M13 9PL, UK \\ E-mail: r.braithwaite@man.ac.uk \\ ${ }^{2}$ Centre for Air Transport and the Environment, Dalton Research Institute, Manchester Metropolitan University, \\ Manchester M1 5GD, UK
}

\begin{abstract}
We apply the degree-day model to seven glacial regions that offer contrasting conditions and are well documented in the World Glacier Inventory. The regions are: Axel Heiberg Island in Arctic Canada; Svalbard; northern Scandinavia; southern Norway; the Alps; the Caucasus; and New Zealand. We estimate the average equilibrium-line altitude (ELA) for each half-degree latitude/longitude grid square from the median elevations of glaciers within the square and we extrapolate temperature from the UEA/CRU (Climate Research Unit of the University of East Anglia) gridded climatology. Using the degree-day model, we calculate annual accumulation at the ELA, equal to ablation at the ELA, and other quantities like summer mean temperature, length of melt season, balance gradients and the sensitivity of mass balance to temperature and/or precipitation changes. Glaciers can be characterized on a scale from cold-dry (Axel Heiberg Island) to warm-wet (New Zealand) corresponding to the contrast between maritime and continental climates. Mass-balance sensitivities to temperature and/or precipitation changes are relatively small for dry-cold climate and relatively high for warm-wet climate. We could extend the approach to other glacier regions but we note that there are large areas for which ELA data are not available as they are still not covered by the World Glacier Inventory.
\end{abstract}

\section{INTRODUCTION}

Under global warming, increased glacier melting may contribute to a rise in global sea level over the coming century (Church and others, 2001). Despite much effort (Oerlemans and Fortuin, 1992; Zuo and Oerlemans, 1997; Gregory and Oerlemans, 1998; Van de Wal and Wild, 2001; Braithwaite and Raper, 2002; de Woul and Hock, 2005; Raper and Braithwaite, 2006), there is still no general agreement on how to calculate changes in glacier melting for projections of future sea level. Most people would probably agree, however, that the ultimate aim is to develop a glacier melt model that can (1) receive input from a Global Climate Model (GCM), and (2) provide output to a model of glacier dynamics and/or geometry.

Mountain glaciers and ice caps are usually much smaller than GCM grid resolution, and probably the best way to treat them is to aggregate glacier areas into larger units. For example, Oerlemans and Fortuin (1992) regressed massbalance sensitivity (calculated for 12 glaciers with an energy-balance model) onto precipitation and applied the (non-linear) equation to 100 glacier regions of varying size, from Ellesmere Island $\left(80000 \mathrm{~km}^{2}\right)$ to Mount Kenya $\left(1 \mathrm{~km}^{2}\right)$. Zuo and Oerlemans (1997), Gregory and Oerlemans (1998) and Van de Wal and Wild (2001) apply GCM results to these same 100 regions. This involves some clumsy interpolation because of the different sizes of the regions, and there is also the question of variations within the larger regions. Braithwaite and Raper (2002) and Raper and Braithwaite (2006) propose a gridded approach based on G. Cogley's estimate of glacier areas within $1^{\circ}$ grid squares (GGHYDRO Release 2.2, ftp://ftp.trentu.ca/pub/gghydro), which covers all glacierized areas outside Greenland and Antarctica. We now extend this approach by applying the degree-day model to $0.5^{\circ}$ gridded data within some selected regions. We choose to work at $0.5^{\circ}$ because a climatology (New and others, 1999) is available at this scale and because we can aggregate results again to fit a coarser grid if the analysis reveals fairly small variations at the $0.5^{\circ}$ gridscale.

\section{EQUILIBRIUM-LINE ALTITUDE (ELA)}

The ELA is the altitude on a glacier at which the mass balance (specific balance) is zero with annual ablation equal to annual accumulation. ELA is routinely measured in glacier mass-balance studies and is generally found to fluctuate quite widely from year to year on the same glacier.

Aside from its role in mass-balance study, the ELA is related to the annual snowline, sometimes called firn line, which has been discussed since the 18th century. Kurowski (1891) suggested that the firn line is approximately equal to the arithmetic mean altitude of the glacier (1) when the glacier is in balance and (2) when mass balance is a linear function of altitude. For a glacier with an approximately symmetrical distribution of area with altitude, the mean elevation is approximately equal to the median elevation, i.e. the altitude with accumulation-area ratio $\mathrm{AAR}=0.5$. The median glacier altitude, mistakenly referred to as 'mean' elevation, was therefore recommended for inclusion in the World Glacier Inventory (Müller and others, 1977), and data are now available for many thousands of glaciers in different parts of the world.

If we take a minimum of 5 years of record as roughly 'representative' of the ELA for the glacier in question, we have data for 144 glaciers, based on mass-balance data from Braithwaite (2002) and Dyurgerov and others (2002). The choice of 5 years of record is a judgment call, as a shorter series of ELA data may be unduly influenced by a single anomalous year, while restricting ourselves to longer series will greatly reduce the number of glaciers considered. Plotting these ELA values against median glacier elevation 


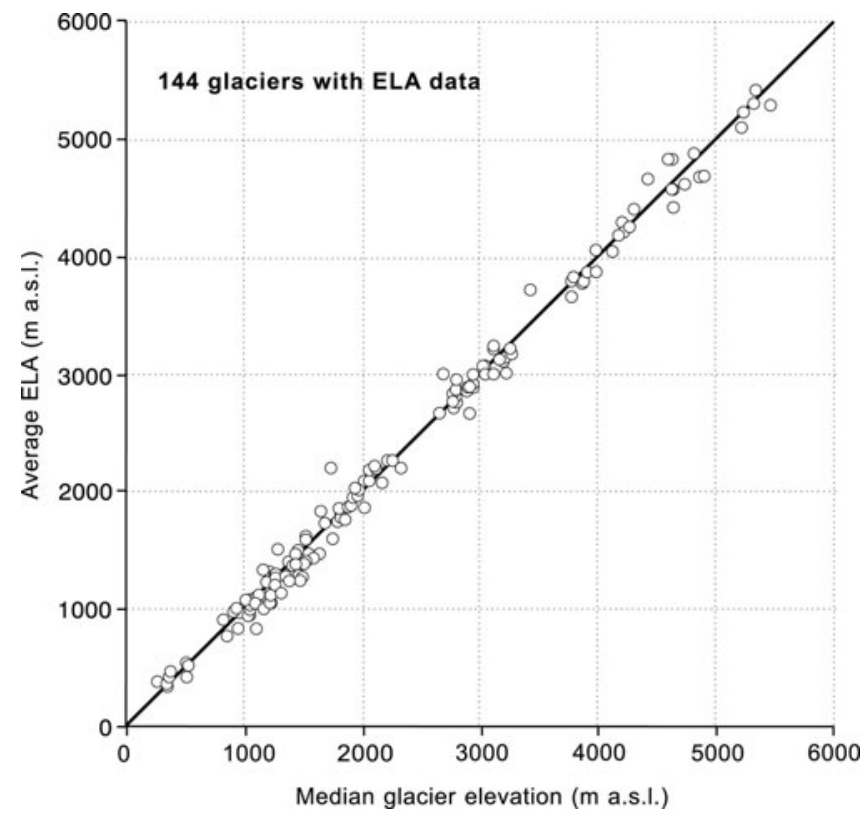

Fig. 1. Correlation between observed ELA and median glacier elevation. The observed ELA refers to glaciers where ELA has been measured for at least 5 years as part of a mass-balance measurement programme.

(Fig. 1) shows that the two concepts are highly correlated across a wide range of glacial conditions from the Arctic to the highlands of central Asia. The regression equation between observed ELA and median elevation in Figure 1 is very close to $1: 1$. The median elevation should therefore express the broad geographical variations in ELA that we need for our study. For detailed studies of single glaciers, or small regions, however, it may be worth working out various 'corrections' to apply to the median elevation. For example, Braithwaite and Müller (1980) found a range of AARs for steady-state ELA, with higher values for continental glaciers and lower values for maritime glaciers. However, most glaciers are 'fat near the middle', so a large difference in AAR only changes ELA by a few tens of metres.

For this study we wanted several regions that are well defined and well covered in the World Glacier Inventory (World Glacier Monitoring System, University of Zürich, Switzerland, http://nsidc.org/NOAA/wgms_inventory). The five major regions of European glacierization from Svalbard to the Caucasus were obvious candidates, and we added Axel Heiberg Island and New Zealand to represent extreme cases. We extracted data from the World Glacier Inventory for the chosen regions (Table 1). ELAs for individual glaciers were averaged for the same $0.5^{\circ}$ latitude/longitude grid squares as used in the $0.5^{\circ}$ climatology of New and others (1999). The ranges of estimated ELAs in Table 1 refer to the grid square averages of median glacier elevation.

\section{DEGREE-DAY MODEL}

Various forms of the degree-day model have been applied to mountain glaciers and ice caps (Hock, 2003) and to the Greenland ice sheet (Marshall, 2006). The 'physics' of the model in terms of surface energy balance is discussed by Braithwaite (1981, 1995) and Braithwaite and Olesen (1990).

The present paper is part of the same study as Braithwaite and others (2006), which is a follow-up to earlier work by Braithwaite and others (2003). In the earlier work, the degree-day model is tuned by fitting the model to the observed distribution of mass balance vs altitude. However, such data are only available for relatively few glaciers (e.g. 61 glaciers (Braithwaite and others, 2002)). Braithwaite and others (2006) therefore relocate the model to the glacier ELA where accumulation is equal to the ablation calculated with the degree-day model. If we further assume that the ELA is approximated by the median glacier altitude (Fig. 1), we can apply the degree-day model to thousands of glaciers for which data are available.

The temperature at the ELA is estimated by extrapolating temperature from the gridded climatology of New and others (1999) using a vertical lapse rate. We apply an empirical 'cooling effect' to account for the observed temperature difference between a glacier weather station and a station on ice-free land at the same altitude (Braithwaite, 1980). The sum of positive temperature and the probability of freezing temperature at the ELA are calculated from monthly mean temperature assuming that temperature is normally distributed within the month (Braithwaite, 1985). The melting of snow and ice is calculated from the annual sum of positive temperature using different degree-day factors (DDFs) for ice and snow (Braithwaite, 1995), and snow accumulation at the ELA is set identical to the calculated snowmelt. More generally, snow accumulation is the annual sum of monthly precipitation multiplied by monthly probability of freezing taken from the degree-day model. We invert this relationship to calculate precipitation at the ELA from accumulation, assuming that the precipitation at the ELA follows the same annual

Table 1. Summary data for the seven glacier regions extracted from the World Glacier Inventory. ELA is estimated from median glacier elevation or the average of maximum and minimum elevation

\begin{tabular}{|c|c|c|c|c|}
\hline Region & Location & $\begin{array}{c}\text { ELA } \\
\text { ma.s.l. }\end{array}$ & $\begin{array}{c}\text { Glacier area } \\
\mathrm{km}^{2}\end{array}$ & Number of grid squares \\
\hline Axel Heiberg Island & $78-81^{\circ} \mathrm{N}, 88-96^{\circ} \mathrm{W}$ & $150-1087$ & 11695 & 67 \\
\hline Svalbard & $76-80^{\circ} \mathrm{N}, 10-27^{\circ} \mathrm{E}$ & $110-760$ & 29808 & 95 \\
\hline Northern Scandinavia & $65-70^{\circ} \mathrm{N}, 13-23^{\circ} \mathrm{E}$ & $700-1530$ & 1447 & 72 \\
\hline Southern Norway & $59-63^{\circ} \mathrm{N}, 5-9^{\circ} \mathrm{E}$ & 1010-1890 & 1558 & 33 \\
\hline The Alps & $44-47^{\circ} \mathrm{N}, 5-14^{\circ} \mathrm{E}$ & 2100-3120 & 3051 & 47 \\
\hline The Caucasus & $41-44^{\circ} \mathrm{N}, 40-48^{\circ} \mathrm{E}$ & 2530-3980 & 972 & 28 \\
\hline New Zealand & $41-46^{\circ} \mathrm{S}, 167-174^{\circ} \mathrm{W}$ & $1490-2440$ & 1159 & 25 \\
\hline
\end{tabular}




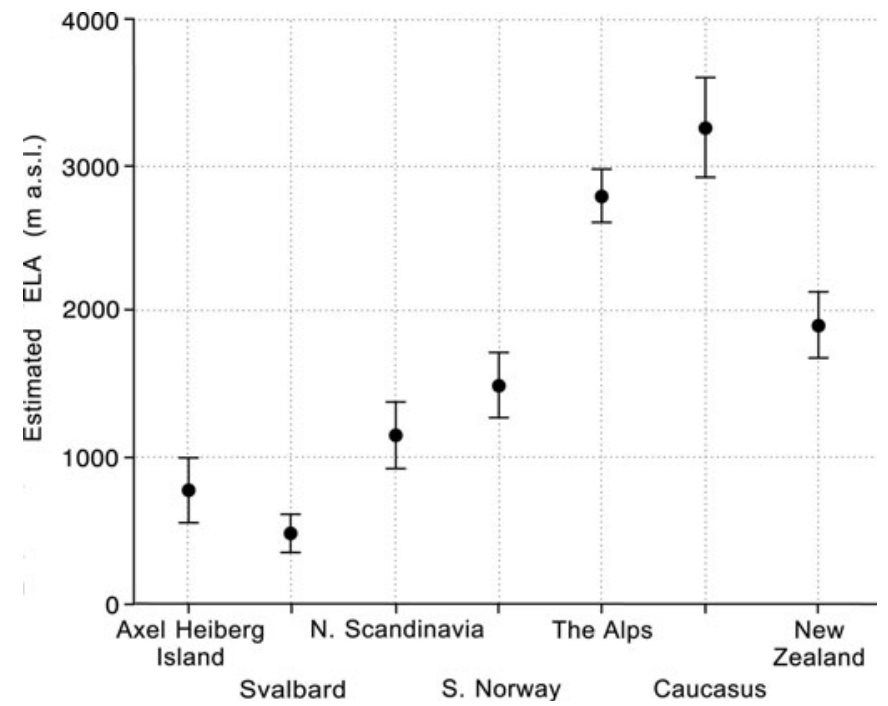

Fig. 2. Estimated ELA for seven glacial regions. ELA is estimated from median glacier elevation in the World Glacier Inventory, or from maximum and minimum glacier elevation. Error bars represent standard deviation.

distribution as the precipitation in the gridded climatology. Calculated in this way, the annual precipitation at the ELA ('glacier precipitation') is generally greater than the precipitation in the gridded climatology ('grid precipitation') and this probably reflects a real increase of precipitation with altitude (Braithwaite and others, 2002).

The above model involves several potential errors and it would be foolish to apply the degree-day model uncritically. Braithwaite and others (2006) attempt to verify the model by comparing calculated accumulation with observed winter balance, although accumulation and winter balance are not identical concepts,. They found that uncertainties in vertical lapse rate (VLR) and DDF for snow need not have a large effect on calculations of annual accumulation if low, medium and high VLRs are paired with low, medium and high DDFs. For further work, we adopt the medium estimates of VLR and DDF from Braithwaite and others (2006): $6.5 \mathrm{~K} \mathrm{~km}^{-1}$ for VLR and $4 \mathrm{~mm} \mathrm{~d}^{-1} \mathrm{~K}^{-1}$ for DDF. This DDF is well within the range of observed values (Hock, 2003). Braithwaite and others (2006) find generally good agreement for the 180 glaciers where winter balance data are available, and the agreement improves when both are averaged for the five large regions (Arctic, North America, Iceland, Europe and former Soviet Union/Asia) from which most mass-balance data are available.

\section{RESULTS FOR THE SEVEN REGIONS}

The degree-day model was applied to the ELA and climate data for each $0.5^{\circ}$ grid square in each of the seven regions. The main variables calculated by the model are listed in Table 2. The ELAs for the seven regions are shown in Figure 2 where the error bars refer to standard deviation. There is obviously considerable variation within each region as well as between regions. For example, several of the regions show broad geographical trends and effects of aspect that deserve further examination in a future study. Axel Heiberg Island and Svalbard both represent 'Arctic' regions, but ELAs are notably higher in Axel Heiberg Island. There is also a clear trend of rising ELA as one goes south from Svalbard to

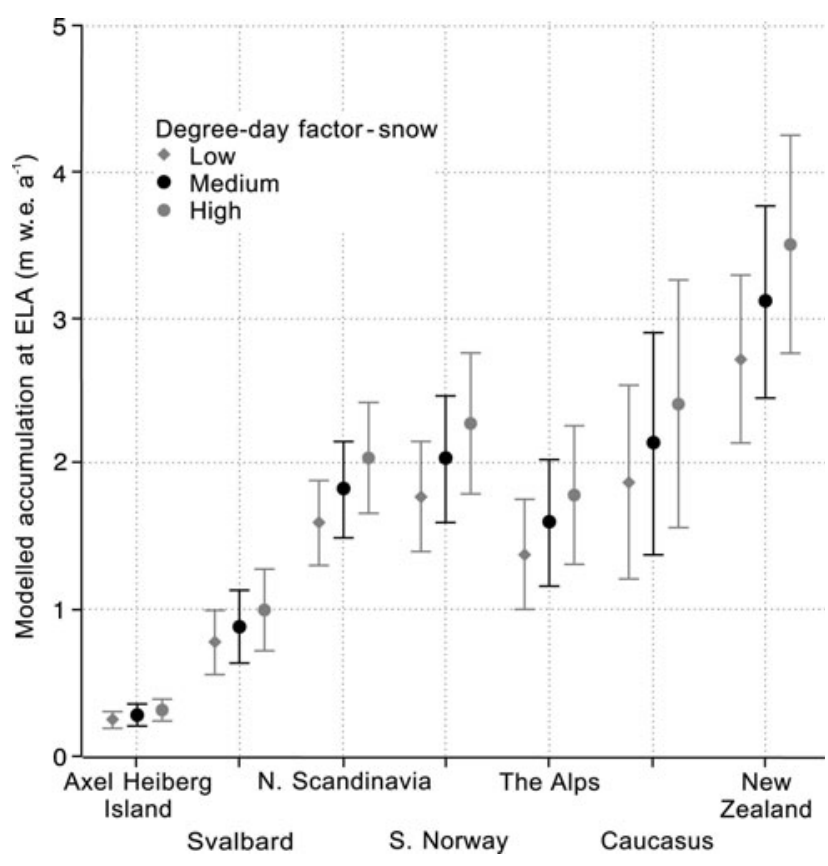

Fig. 3. Accumulation at the ELA calculated by the degree-day model for seven glacial regions. Low, medium and high values of DDF for snow are 3.5, 4 and $4.5 \mathrm{~mm} \mathrm{~d}^{-1} \mathrm{~K}^{-1}$. Error bars represent standard deviation.

the Caucasus, no doubt reflecting the trend of rising temperature in the large-scale atmosphere.

The calculated accumulation at the ELA (Fig. 3) shows wide variations between regions as well as within regions. In addition to a medium value of DDF for snow $\left(4 \mathrm{~mm} \mathrm{~d}^{-1} \mathrm{~K}^{-1}\right)$, parallel calculations for low and high DDF are made for a sensitivity study. Model accumulation obviously increases with assumed DDF, but this does not change the basic pattern of variability: Axel Heiberg Island has the lowest accumulation and New Zealand has the highest. As low accumulation at the ELA implies low melt, we can interpret the pattern in Figure 3 as a transition from cold-dry to warmwet. Axel Heiberg Island is obviously drier than Svalbard, and its ELAs are consequently higher. There is surprisingly little difference in accumulation between northern Scandinavia, southern Norway, the Alps and the Caucasus, which probably explains why the ELA is so much higher for the Caucasus, with higher equivalent-altitude temperatures. The high accumulation for New Zealand glaciers no doubt accounts for the relatively low ELA in Figure 2.

After the degree-day model calculates glacier precipitation, the effect of a $1 \mathrm{~K}$ temperature change is simulated by

Table 2. Main variables calculated by degree-day model

June-August mean temperature at ELA Annual mean temperature at ELA Days with positive temperature at ELA Annual accumulation at ELA Annual precipitation at ELA $\mathrm{MB}$ sensitivity to $+1 \mathrm{~K}$ change $M B$ sensitivity to $+1 \mathrm{~K}$ for June-August $\mathrm{MB}$ sensitivity to $+10 \%$ precipitation Balance gradient in upper ablation area Balance gradient in lower accumulation area 


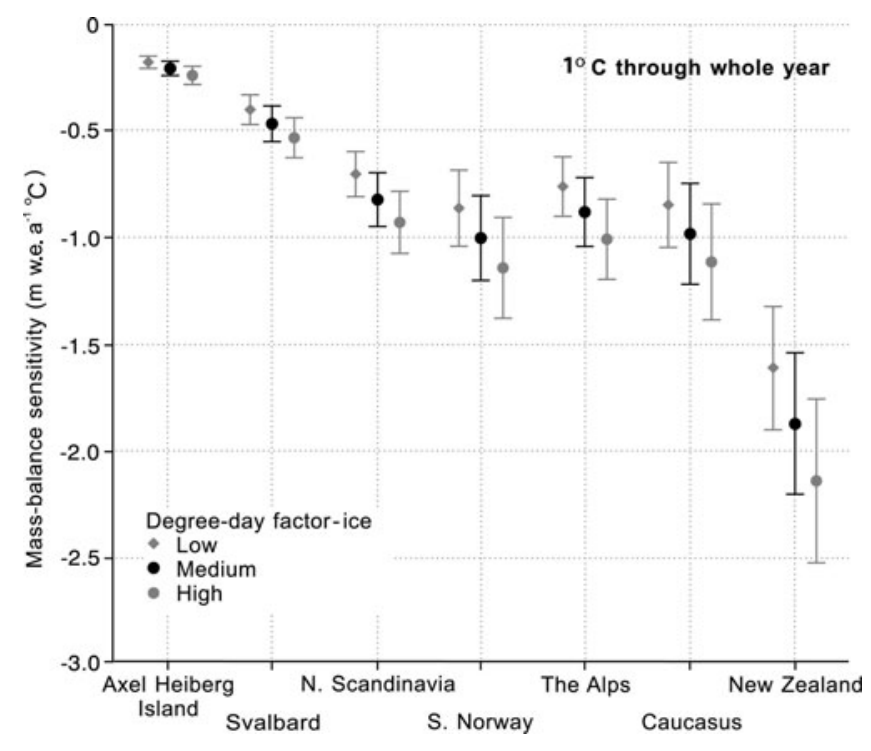

Fig. 4. Temperature sensitivity of mass balance calculated by the degree-day model for seven glacial regions. Sensitivity refers to a $1^{\circ} \mathrm{C}$ temperature change throughout the whole year. Low, medium and high values of DDF for ice are 6, 7 and $8 \mathrm{~mm} \mathrm{~d}^{-1} \mathrm{~K}^{-1}$. Error bars represent standard deviation.

increasing temperature and recalculating accumulation (for the same glacier precipitation) and ablation at the same altitude as before, i.e. at what was the ELA where mass balance is now negative. Mass-balance sensitivity for two different temperature changes is considered, $1 \mathrm{~K}$ for the whole year and $1 \mathrm{~K}$ for the summer months June-August, but we only show results for the former (Fig. 4) as the two concepts are well correlated. The mass-balance sensitivity for a $10 \%$ precipitation increase is also well correlated with the other two sensitivities. As the increased melt at the former ELA is in the form of ice melt, the mass-balance sensitivity for temperature depends upon the DDF for melting ice. Aside from our preferred 'medium' estimate of $7 \mathrm{~mm} \mathrm{~d}^{-1} \mathrm{~K}^{-1}$, we make parallel calculations for low and high DDFs for melting ice $\left(6\right.$ and $\left.8 \mathrm{~mm} \mathrm{~d}^{-1} \mathrm{~K}^{-1}\right)$ which are well within the range of observed values (Hock, 2003). Mass-balance sensitivity obviously increases with assumed DDF, but this does not change the basic pattern in Figure 4. The cold-dry environments (Axel Heiberg Island and Svalbard) have low mass-balance sensitivity, while New Zealand (warm-wet) has extremely high mass-balance sensitivity. Aside from New Zealand, the other results are in good agreement with previous estimates from Oerlemans and Fortuin (1992) and Braithwaite and others (2002) (for 12 and 61 glaciers respectively). The high mass-balance sensitivity for New Zealand agrees with the high sensitivity found for Icelandic glaciers by de Woul and Hock (2005), so we should all adjust our ideas in that direction.

The degree-day model has the facility to calculate balance gradients in the upper ablation and lower accumulations areas respectively, i.e. from $100 \mathrm{~m}$ below the ELA to $100 \mathrm{~m}$ above it. The calculations are approximate because they assume that precipitation is constant in the $200 \mathrm{~m}$ altitude band around the ELA. Results (Fig. 5) confirm that balance gradients in the upper ablation area are significantly higher than in the lower accumulation area, with a general increase in balance gradients from cold-dry to warm-wet environments. The results agree with ranges given by Schytt

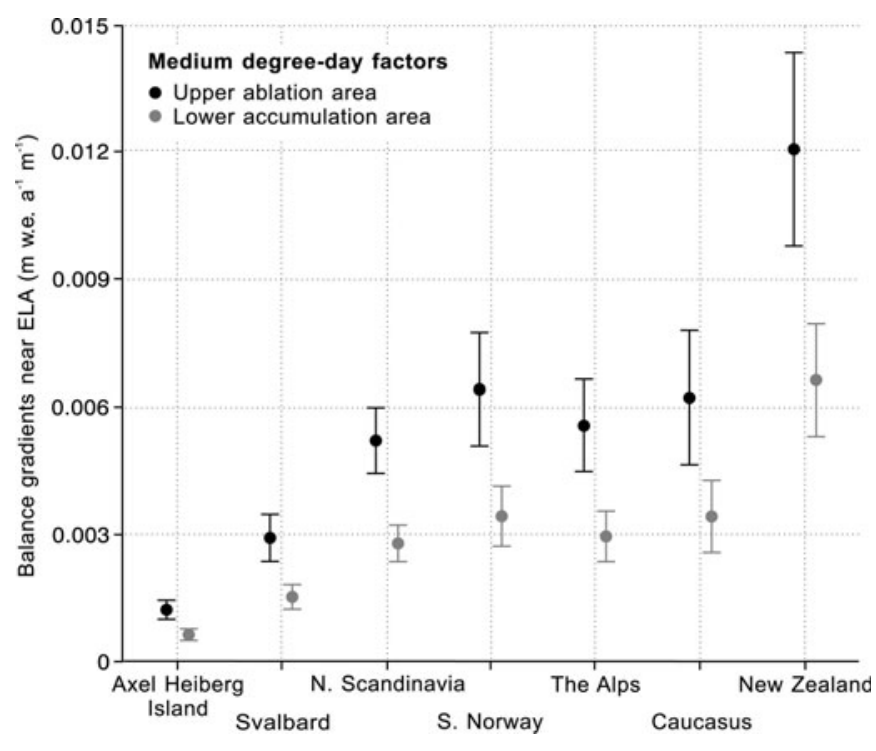

Fig. 5. Balance gradients near the ELA calculated by the degree-day model for seven glacial regions. Upper ablation area is $100 \mathrm{~m}$ altitude band below ELA, and lower accumulation area is $100 \mathrm{~m}$ altitude above ELA. Medium DDFs for snow and ice are used, i.e. 4 and $7 \mathrm{~mm} \mathrm{~d}^{-1} \mathrm{~K}^{-1}$. Error bars represent standard deviation.

(1967) who ascribed higher ablation gradients to maritime glaciers and lower values to continental glaciers. A claimed difference between balance gradients in ablation and accumulation areas is the basis of the 'balance ratio' method of determining the ELA of former glaciers (Furbish and Andrews, 1984), but our choice of DDFs gives a ratio (Fig. 5) somewhat less than their preferred value of 2 .

\section{DISCUSSION AND CONCLUSIONS}

The average conditions in the seven regions are summarized in Table 3. The annual temperature range is often taken as an index of maritime/continental climate (outside the tropics), and with the exception of the Caucasus the trend is for decreasing temperature range as we move down the list. The apparently anomalous temperature range for the Caucasus covers a wide variation within the region. The well-known association between summer mean temperature and annual accumulation (Ohmura and others, 1992) is obvious in Table 3, with a trend from cold-dry to warm-wet, and there is a nearly parallel increase in duration of melt season and mass-balance sensitivity. The mass-balance sensitivity is a combination of changes in annual ablation and accumulation (not shown), with both increasing down Table 3. For example, the high average mass-balance sensitivity for New Zealand $\left(-1.87 \mathrm{~m} \mathrm{a}^{-1} \mathrm{~K}^{-1}\right)$ is made up of sensitivities of -0.40 and $-1.47 \mathrm{~m} \mathrm{a}^{-1} \mathrm{~K}^{-1}$ for accumulation and ablation respectively.

We have chosen to present our results as averages for the different regions (Figs 3-5) and to interpret them in terms of a transition from cold-dry to warm-wet conditions. We could have presented our results in terms of correlations with grid precipitation, but there is not enough space to give the relevant scatter diagrams in this short paper. The following correlation coefficients must suffice: annual accumulation and grid precipitation $r=0.77$; mass-balance sensitivity and grid precipitation $r=-0.87$; balance gradient in upper ablation area and grid precipitation $r=0.87$; 
Table 3. Summary of glaciological characteristics for the seven regions as calculated by the degree-day model using medium estimates of vertical lapse rate and DDFs. Numbers refer to averages over all grid squares in each region

\begin{tabular}{|c|c|c|c|c|c|c|}
\hline Region & Grid squares & $\begin{array}{c}\text { Annual temperature } \\
\text { range } \\
{ }^{\circ} \mathrm{C}\end{array}$ & $\begin{array}{c}\text { Duration of melt } \\
\text { season at ELA } \\
\text { days }\end{array}$ & $\begin{array}{c}\text { Summer tempera- } \\
\text { ture at ELA } \\
{ }^{\circ} \mathrm{C}\end{array}$ & $\begin{array}{c}\text { Annual accumul- } \\
\text { ation at ELA } \\
\mathrm{m} \mathrm{a}^{-1}\end{array}$ & $\begin{array}{c}\text { Mass-balance } \\
\text { sensitivity at ELA } \\
\mathrm{m} \mathrm{a}^{-1} \mathrm{~K}^{-1}\end{array}$ \\
\hline Axel Heiberg Island & 67 & 40 & 27 & -2.4 & 0.29 & -0.20 \\
\hline Svalbard & 95 & 23 & 63 & 0.9 & 0.90 & -0.46 \\
\hline Northern Scandinavia & 72 & 22 & 104 & 3.7 & 1.83 & -0.81 \\
\hline Southern Norway & 33 & 18 & 122 & 3.6 & 2.05 & -1.00 \\
\hline Alps & 47 & 16 & 106 & 2.3 & 1.60 & -0.87 \\
\hline Caucasus & 28 & 26 & 116 & 4.0 & 2.16 & -0.97 \\
\hline New Zealand & 25 & 11 & 184 & 4.2 & 3.12 & -1.87 \\
\hline
\end{tabular}

balance gradient in lower accumulation area and grid precipitation $r=0.87$. All sample sizes are 367 and all four correlations are significant at $<1 \%$ probability. With such high correlations it should be possible to extrapolate glaciological conditions from the seven regions to the rest of the world (with known grid precipitation) using the appropriate regression equation as Raper and Braithwaite (2006) did for balance gradient.

There are other areas, notably the Gulf of Alaska (Arendt and others, 2002) and Patagonia (Rignot and others, 2003), where high mass-balance sensitivity similar to New Zealand and Iceland might prevail over large areas and could contribute substantial rises in global sea level. In principle, we could extend our modelling approach to cover the entire world, but there are large areas that are still not covered by glacier inventory, especially in Canada and the USA as well as 'local glaciers' in Greenland and Antarctica. The glacier inventory work in both Canada and the USA probably 'bogged down' in the face of the overwhelming amount of detailed data that had to be included. However, if the relevant agencies were aware that we only need a single glacier elevation (e.g. median elevation) and a total area, they may be motivated to complete a 'useful minimum' inventory. Alternatively, we will investigate ways of applying the degree-day model to regions where glacier inventory data are lacking. We thereby hope to apply the degree-day model to all mountain glaciers and ice caps in the world.

\section{ACKNOWLEDGEMENTS}

The UK Natural Environment Research Council (grant GR9/ 01777) and European Commission (grant ENV4-CT95-0124) supported early development work on the degree-day model at the University of Manchester, but recent work has been unfunded.

\section{REFERENCES}

Arendt, A.A., K.A. Echelmeyer, W.D. Harrison, C.S. Lingle and V.B. Valentine. 2002. Rapid wastage of Alaska glaciers and their contribution to rising sea level. Science, 297(5580), 382-386.

Braithwaite, R.J. 1980. Correspondence. Glacier energy balance and air temperature: comments on a paper by Dr M. Kuhn. J. Glaciol., 25(93), 501-503.

Braithwaite, R.J. 1981. On glacier energy balance, ablation, and air temperature. J. Glaciol., 27(97), 381-391.

Braithwaite, R.J. 1985. Calculation of degree-days for glacierclimate research. Z. Gletscherkd. Glazialgeol., 20, 1-8.
Braithwaite, R.J. 1995. Positive degree-day factors for ablation on the Greenland ice sheet studied by energy-balance modelling. J. Glaciol., 41(137), 153-160.

Braithwaite, R.J. 2002. Glacier mass balance: the first 50 years of international monitoring. Progr. Phys. Geogr., 26(1), 76-95.

Braithwaite, R.J. and F. Müller. 1980. On the parameterization of glacier equilibrium line altitude. IAHS Publ. 126 (Riederalp Workshop 1978 - World Glacier Inventory), 263-271.

Braithwaite, R.J. and O.B. Olesen. 1990. Response of the energy balance on the margin of the Greenland ice sheet to temperature changes. J. Glaciol., 36(123), 217-221.

Braithwaite, R.J. and S.C.B. Raper. 2002. Glaciers and their contribution to sea level change. Phys. Chem. Earth, 27(3234), 1445-1454.

Braithwaite, R.J., Y. Zhang and S.C.B. Raper. 2002. Temperature sensitivity of the mass balance of mountain glaciers and ice caps as a climatological characteristic. Z. Gletscherkd. Glazialgeol., 38(1), 35-61.

Braithwaite, R.J., S.C.B. Raper and K. Chutko. 2006. Accumulation at the equilibrium-line altitude of glaciers inferred from a degree-day model and tested against field observations. Ann. Glaciol., 43, 329-334.

Church, J.A. and 7 others. 2001. Changes in sea level. In Houghton, J.T. and 7 others, eds. Climate change 2001: the scientific basis. Contribution of Working Group I to the Third Assessment Report of the Intergovernmental Panel on Climate Change. Cambridge, etc., Cambridge University Press, 639-693.

De Woul, M. and R. Hock. 2005. Static mass-balance sensitivity of Arctic glaciers and ice caps using a degree-day approach. Ann. Glaciol., 42, 217-224.

Dyurgerov, M., M. Meier and R. Armstrong, eds. 2002. Glacier mass balance and regime: data of measurements and analysis. Boulder, CO, University of Colorado. Institute of Arctic and Alpine Research. (INSTAAR Occasional Paper 55.)

Furbish, D.J. and J.T. Andrews. 1984. The use of hypsometry to indicate long-term stability and response of valley glaciers to changes in mass transfer. J. Glaciol., 30(105), 199-211.

Gregory, J.M. and J. Oerlemans. 1998. Simulated future sea-level rise due to glacier melt based on regionally and seasonally resolved temperature changes. Nature, 391(6666), 474-476.

Hock, R. 2003. Temperature index melt modelling in mountain areas. J. Hydrol., 282(1-4), 104-115.

Kurowski, L. 1891. Die Höhe der Schneegrenze mit besonderer Berücksichtigung der Finsteraarhorn-Gruppe. Penck's Geogr. Abh., 5(1), 119-160.

Marshall, S.J. 2006. Modelling glacier response to climate change. In Knight, P.G., ed. Glacier science and environmental change. Oxford, Blackwell Publishing, 163-173.

Müller, F., T. Caflisch and G. Müller. 1977. Instructions for the compilation and assemblage of data for a world glacier inventory. Zürich, ETH Zürich. Temporary Technical Secretariat for the World Glacier Inventory. 
New, M., M. Hulme and P. Jones. 1999. Representing twentieth century space-time climate variability. I. Development of a 1961-1990 mean monthly terrestrial climatology. J. Climate, 12(3), 829-856.

Oerlemans, J. and J.P.F. Fortuin. 1992. Sensitivity of glaciers and small ice caps to greenhouse warming. Science, 258(5079), 115-117.

Ohmura, A., P. Kasser and M. Funk. 1992. Climate at the equilibrium line of glaciers. J. Glaciol., 38(130), 397-411.

Raper, S.C.B. and R.J. Braithwaite. 2006. Low sea level rise projections from mountain glaciers and icecaps under global warming. Nature, 439(7074), 311-313.
Rignot, E., A. Rivera and G. Casassa. 2003. Contribution of the Patagonian icefields of South America to sea level rise. Science, 302(5644), 434-437.

Schytt, V. 1967. A study of "ablation gradient". Geogr. Ann., 49A $(2-4), 327-332$

Van de Wal, R.S.W. and M. Wild. 2001. Modeling the response of glaciers to climate change by applying volume-area scaling in combination with a high resolution GCM. Climate Dyn., 18(3-4), 359-366.

Zuo, Z. and J. Oerlemans. 1997. Contribution of glacier melt to sealevel rise since AD 1865: a regionally differentiated calculation. Climate Dyn., 13(12), 835-845. 